\title{
Bioresorbable stents: quo vantis?
}

\author{
Nicholas G. Kounis ${ }^{1}$, Ioanna Koniari ${ }^{2}$, Periklis Davlouros ${ }^{1}$, George Soufras ${ }^{1}$, Grigorios Tsigkas ${ }^{1}$, George Hahalis ${ }^{1}$ \\ ${ }^{1}$ Department of Cardiology, University of Patras Medical School, Rion, Patras, Achaia, Greece; ${ }^{2}$ Department of Cardiology, Royal Bromptom \\ Hospital, London, UK \\ Correspondence to: Nicholas G. Kounis, MD, PhD. Department of Cardiology, University of Patras Medical School, Queen Olgas Square, 7 Aratou \\ Street, Patras, Achaia, Greece. Email: ngkounis@otenet.gr. \\ Response to: Katsikis A, Serruys PW. Bioresorbable scaffolds versus metallic stents in routine PCI: the plot thickens. J Thorac Dis 2017;9:2296-300.
}

Submitted Oct 01, 2017. Accepted for publication Oct 07, 2017.

doi: $10.21037 /$ jtd.2017.10.62

View this article at: http://dx.doi.org/10.21037/jtd.2017.10.62

The bioresorbable scaffolds have been introduced recently in an effort to eliminated metals from the coronary arteries, to maintain vessel pulsatility and to diminish late and especially very late stent thrombosis.

However, an alarming increase of 3.5 times higher rate of thrombosis with bioresorbable stents has been shown recently in several meta-analyses and reports (1) when compare everolimus-eluting bioresorbable vascular scaffolds with everolimus-eluting metallic stents. Furthermore, a significant higher rate target lesion failure in patients who received bioresorbable scaffolds has been also observed.

In the very interesting editorial published recently in Fournal of Thoracic disease (2), the authors, commenting on the higher rate of thrombosis with the Abbott's Absorb bioresorbable scaffold, wisely characterized this event as a double blow. Firstly, due to increased thrombotic complications and secondly due to the fact that we don't know the causes of this phenomenon and most important how to deal with it.

Indeed, the results of two most recent meta-analyses with the same median follow-up time-2nd and 3rd year the first (3) and 1 st and 2 years the second (4), the same number of patients [5,583], the same number of randomized trials [7] 5 of which were conducted by the same authors and 2 by different authors, are shown in the Table 1. The differences against bioresorbable scaffolds have been attributed to early discontinuation of dual antiplatelet therapy, strut thickness, potential malposition, late discontinuity, peristrut low-intensity area, uncovered strut, underdeployment, incomplete lesion coverage, recoil, restenosis, and very small vessel.

The currently used Absorb GT1 Bioresorbable
Vascular Scaffold system is composed of bioresorbable poly (L-lactide) backbone coated by bioresorbable poly (D,L-lactide) containing the antineoplastic everolimus substance. In order to facilitate fluoroscopic visualization, four platinum marker beads have been embedded, by two, at both the proximal and distal ends of the scaffold. Despite that all this system is scheduled to be absorbed in less than 1 year, polymer remnants have been traced, by Fourier transform IR spectroscopy, 44 months after scaffold implantation (5). The final degradation product of the two polymers is lactic acid which finally metabolizes into carbon dioxide and water through the Krebs cycle. All above components have been associated with the following pathophysiologic consequences: (I) low-molecular weight poly (L-lactide) scaffolds that is more susceptible to hydrolysis, can induce intense inflammatory reaction, whereas high-molecular weight are associated with minimal inflammatory reaction (6); (II) poly (L-lactide) acid screws, used in orthopedics, have been reported to induce systemic hypersensitivity reactions proven by positive skin tests and necessitated to remove the screws (7); (III) poly (L-lactide) gel injections have been incriminated as inducing tissue granulomatous reactions (8); (IV) lactic acid can decrease the $\mathrm{pH}$ of the surrounding tissue, fact that could trigger inflammatory and foreign body reaction (9); (V) the sensory neurons innervating the heart bring molecular lactic acid sensors and when these sensors are stimulated by lactic acid can result in similar pain with that encountered in coronary syndromes (10); (VI) the carbon dioxide can enhance acidosis that can cause thrombosis as it has been occurred in open thorax surgery (11); (VII) hypersensitivity pneumonitis, atopic dermatitis, exanthema and generalized 
Table 1 Two-year thrombosis and target lesion failure rates with everolimus-eluting bioresorbable vascular scaffolds and everolimuseluting metallic stents in two recent meta-analyses

\begin{tabular}{lccc}
\hline Meta-analyses & ST (\%) & TLF (\%) & TVRMI (\%) \\
\hline LANCET $^{2}$ & & & \\
BVS & 2.3 & 5.3 & 5.8 \\
EES & 0.7 & 3.9 & 3.2 \\
JACC $^{1}$ & & & \\
BVS & 2.4 & 9.6 & NA \\
EES & 0.7 & 7.2 & NA \\
\hline
\end{tabular}

${ }^{1}$, conducted by the same authors; ${ }^{2}$, conducted by different authors. ST, stent thrombosis; TLF, target lesion failure; TVRMI, target vessel recanalization myocardial infarction; BVS, bioresorbable vascular scaffolds; EES, everolimus-eluting stents; NA, not applicable.

as well as lingual angioedema have been associated with the use of everolimus substance (12); (VIII) platinum anions and taxanes have been associated with hypersensitivity reactions that have been confirmed by skin tests (13).

The information sheets included in the commercial packages, the special product characteristics and the Food and Drug Administration (FDA) safety alert (14) clearly state that these devices are contraindicated to patients who have hypersensitivity or allergy to everolimus, materials used in the device, such as poly (L-lactide), poly (D,Llactide), contrast media, aspirin, antiplatelet agents or platinum. We are wondering why all these meta-analyses, studies, editorials and reports have not emphasized the above-mentioned information, alerts and pathophysiologic associations that we regard as essential and lifesaving, at least on some instances.

It seems, therefore, that the magic bullet for the treatment of coronary artery disease has not been discovered as yet. It is extremely important to comply with and strictly adhere to FDA recommendations and special product characteristics, together with improvement of current device technology and efforts for inventing inert materials.

\section{Acknowledgements}

None.

\section{Footnote}

Conflicts of Interest: The authors have no conflicts of interest to declare.

\section{References}

1. Wykrzykowska JJ, Kraak RP, Hofma SH, et al. Bioresorbable Scaffolds versus Metallic Stents in Routine PCI. N Engl J Med 2017;376:2319-28.

2. Katsikis A, Serruys PW. Bioresorbable scaffolds versus metallic stents in routine PCI: the plot thickens. J Thorac Dis 2017;9:2296-300.

3. Sorrentino S, Giustino G, Mehran R, et al. EverolimusEluting Bioresorbable Scaffolds Versus Everolimus-Eluting Metallic Stents. J Am Coll Cardiol 2017;69:3055-66.

4. Ali ZA, Serruys PW, Kimura T, et al. 2-year outcomes with the Absorb bioresorbable scaffold for treatment of coronary artery disease:a systematic review and metaanalysis of seven randomised trials with an individual patient data substudy. Lancet 2017;390:760-72.

5. Räber L, Brugaletta S, Yamaji K, et al. Very Late Scaffold Thrombosis:Intracoronary Imaging and Histopathological and Spectroscopic Findings. J Am Coll Cardiol 2015;66:1901-14.

6. Lincoff $M$, Furst $M$, Ellis $M$, et al. Sustained local delivery of dexamethasone by a novel intravascular eluting stent to prevent restenosis in the porcine coronary injury model. J Am Coll Cardiol 1997;29:808-16.

7. Mastrokalos DS, Paessler HH. Allergic reaction to biodegradable interference poly-L-lactic acid screws after anterior cruciate ligament reconstruction with bonepatellar tendon-bone graft. Arthroscopy 2008;24:732-3.

8. Alijotas-Reig J, Garcia-Gimenez V, Vilardell-Tarres M. Late-onset immune-mediated adverse effects after poly-Llactic acid injection in non-HIV patients: clinical findings and long-term follow-up. Dermatology 2009;219:303-8.

9. Barbeck M, Serra T, Booms, P, et al. Analysis of the in vitro degradation and the in vivo tissue response to bilayered 3D-printed scaffolds combining PLA and biphasic PLA/bioglass components-Guidance of the inflammatory response as basis for osteochondral regeneration. Available online: http://dx.doi.org/10.1016/j.bioactmat.2017.06.001

10. Immke DC, McCleskey EW. ASIC3: A Lactic Acid Sensor for Cardiac Pain. Scientific World Journal 2001;1:510-2.

11. Gorter KA, Stehouwer MC, Van Putte BP, et al. Acidosis induced by carbon dioxide insufflation decreases heparin potency:a risk factor for thrombus formation. Perfusion 2017;32:214-9.

12. Kounis NG, Koniari I, Roumeliotis A, et al. Thrombotic responses to coronary stents, bioresorbable scaffolds and the Kounis hypersensitivity-associated acute thrombotic syndrome. J Thorac Dis 2017;9:1155-64. 
13. Brault F, Waton J, Poreaux C, et al. Hypersensitivity to platinum salts and taxanes:The value of skin tests and tolerance induction procedures. Ann Dermatol Venereol 2017;144:685-95.

14. Absorb GT1 ${ }^{\mathrm{TM}}$ Bioresorbable Vascular Scaffold

Cite this article as: Kounis NG, Koniari I, Davlouros P, Soufras G, Tsigkas G, Hahalis G. Bioresorbable stents: quo vantis? J Thorac Dis 2017;9(11):E1032-E1034. doi: 10.21037/ jtd.2017.10.62
(BVS) System. Available online: https://www.fda. gov/medicaldevices/productsandmedicalprocedures/ deviceapprovalsandclearances/recently-approveddevices/ ucm509951.htm 